\title{
Modeling and Simulation of Hydraulic Hammer for Sleeve Valve
}

\author{
Zishan Xu, Guoping Yang \\ Institute of Vehicle Engineering, Shanghai University of Engineering Science, Shanghai, China \\ Email: xuzishan.cool@163.com
}

How to cite this paper: $\mathrm{Xu}, \mathrm{Z}$.S. and Yang, G.P. (2016) Modeling and Simulation of Hydraulic Hammer for Sleeve Valve. Engineering, 8, 657-668.

http://dx.doi.org/10.4236/eng.2016.89059

Received: August 12, 2016

Accepted: September 26, 2016

Published: September 29, 2016

Copyright $\odot 2016$ by authors and Scientific Research Publishing Inc. This work is licensed under the Creative Commons Attribution International License (CC BY 4.0).

http://creativecommons.org/licenses/by/4.0/

(c) (i) Open Access

\begin{abstract}
Hydraulic hammer is commonly used hydraulic equipment in engineering work. The characteristics, high acceleration, high frequency and inertial working pressure, make it greatly different from the working conditions of conventional hydraulic equipment, while hydraulic hammer for sleeve type is also not the same as other hydraulic hammers in structure, efficiency and working performance. Based on the principle of hydraulic hammer for sleeve type, the mathematical model of hydraulic hammer for sleeve type was set with various conditions in the reciprocating movement of piston. In addition, more detailed sketch model can be easily built with the mathematical model in multi-domain system analysis software, AMESim. The simulation system of breaker built based on the principle of power bond graph structures in AMESim system is considered comprehensively to achieve its functions and characteristics, which can quickly realize the calculation of main simulation parameters for impactor. The calculated parameters can be proved to be biased with the test prototype. So these parameters must be optimized by Design Exploration to find the appropriate parameters.
\end{abstract}

\section{Keywords}

Sleeve Type, Modeling, AMESim, Power Bond Graph, Test Verification, Optimizing

\section{Introduction}

Hydraulic hammer is a kind of typical hydraulic impact machine [1]. Its names are different in different countries and companies, mainly including hydraulic hammer, hydraulic impact machine, hydraulic breaker, hydraulic rock breaker and so on. According to Chinese national standard, it is named as hydraulic impact breaker. Although various names as it has, fundamentally it constitutes a complete system with control valve, piston and accumulator, which can realize mutual feedback control between 
control valve and impact piston, automatically completing the straight line reciprocating movement of the piston in the cylinder by transforming from hydraulic energy to kinetic energy of impact piston. Loading to excavator is a common type of work.

Hydraulic hammer is a powerful impact machine which has so many advantages, such as high reliability, strong adaptability, high efficiency, and is convenient to design and maintain. All these superiorities make it applicable in many fields all around the world. Varied type of hydraulic hammer can be divided into 3 types according to the valve structure: column type valve, sleeve valve type and auxiliary valve. The character of column type is that impact hammer and valve are fixed with the common axis, making the whole structure compact. Besides, the movement of the valve is not only controlled by high hydraulic oil, but also by impact hammer sometimes. In addition to the distribution valve, the type with auxiliary valve needs some auxiliary valve acting on the role of auto control and regulation, increasing the stability and reliability of hydraulic rocker. What's more, such type is only found with patent, not applied in product.

\section{Working Principle of Hydraulic Hammer for Sleeve Type [2]}

As showed in Figure 1, high pressure oil flow into the port p, then the back chamber of piston can connect with oil return chamber through sleeve valve. As the acting force in the front chamber is greater than the force in the back chamber, piston would do return movement. When piston moves toward port $4_{1}$, high pressure oil flows into back chamber of sleeve valve from oil passage. Since the sleeve valve in the surface $f_{1}$ are pumped in normally-high-pressure oil, in the surface $\mathrm{f}_{2}$ often through the oil return, in the surface $f_{3}$ through the high-pressure oil at this time. In addition, acting force at the left of sleeve is less than the force at the right, so sleeve would move to the left acting on return movement, because right chamber of piston connects to the high pressure oil at this time, effective area at the right chamber is greater than the left one leading piston for

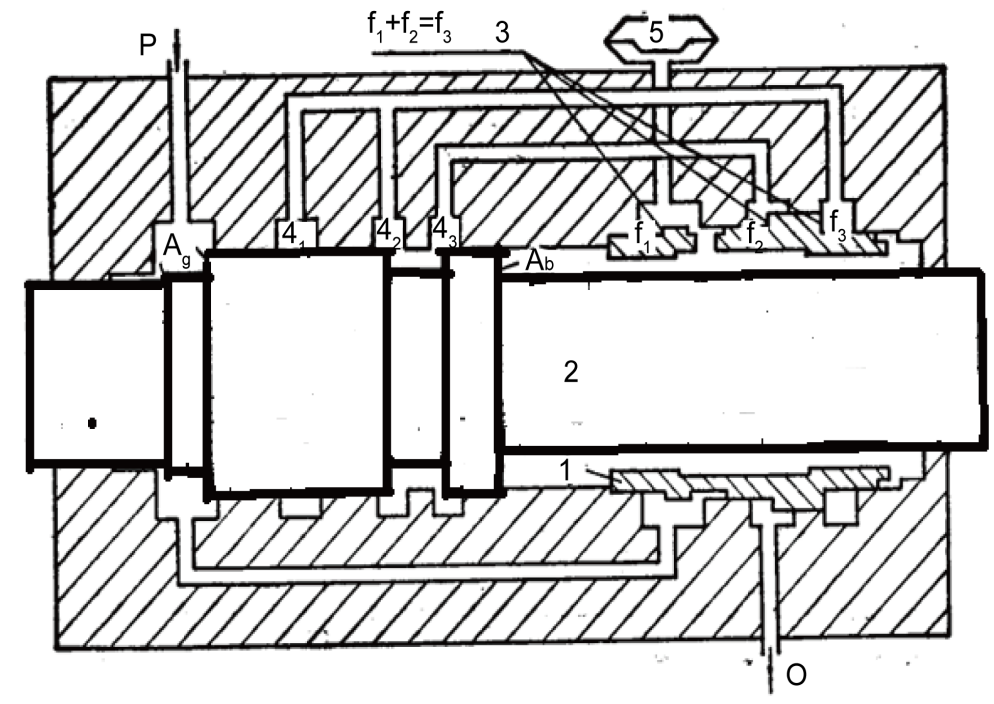

Figure 1. Fundamental diagram of hydraulic hammer for sleeve type. 
return deceleration movement. When piston velocity is zero, acting force the piston put pressure keeps unchanged, and piston would move forward to the left acting on stroke movement. While piston move to the position that annular groove connects the feedback single port $4_{2}$ and $4_{3}$, the sleeve would move forward to the left and piston hit the drill rod similar like the beginning state because the right end connects the return oil hole leading acting force of sleeve at the right end is less than the left end. Such pattern of motion goes in circles. The 3D structure can be showed in Figure 2.

\section{Modeling the Power Bond Graph}

Mechanical parameters $\mathrm{F}, \mathrm{v}$ and fluid parameters are fundamental parameters to compute the system power, which are referred as power-pair parameters. The power-pair parameters of energy storage element such as initial element, volume element have a clear integration relation of differential relation. Not only do they have good message and energy character, but also meet the requirements of the least number of state variables. So it's convenient to take energy storage power-pair parameter (such as F or P) as state variables in the dynamic calculation and analysis [3].

Bond graph-state variable method is a comprehensive analysis of a variety energy research coupling system characteristics, especially for multiple input and multiple output nonlinear systems. In the research on the characteristics of the hydraulic hammer, hydraulic breaker for sleeve valve type can be established by the set of analysis method showed in Figure 3. Various type of physical element and physical process can be divide into five bond element( energy, inertia, capacitive, resistive, transformer) indicting the power distribution net of hydraulic breaker for sleeve type completely.

Pressure change of pressure in the piston chamber and sleeve valve chamber that leads compression and characteristics between sleeve valve and piston chamber change and the whole system leak was fully considered in the power bond graph, besides, the path loss in the chambers and local pressure loss are described in the form of resistance. In addition, coulomb friction and viscous resistance in the movement piston and sleeve valve suffered can also be described. According to the description of power bond graph, mathematical model of hydraulic breaker in the dynamic process should be built which is also named as state equation.

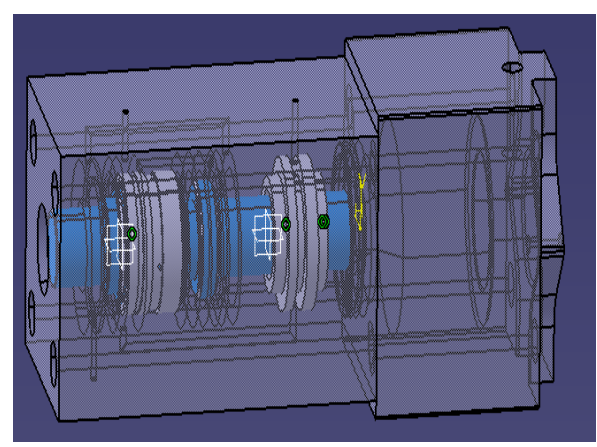

Figure 2. Partial structure graph of hydraulic hammer for sleeve type. 


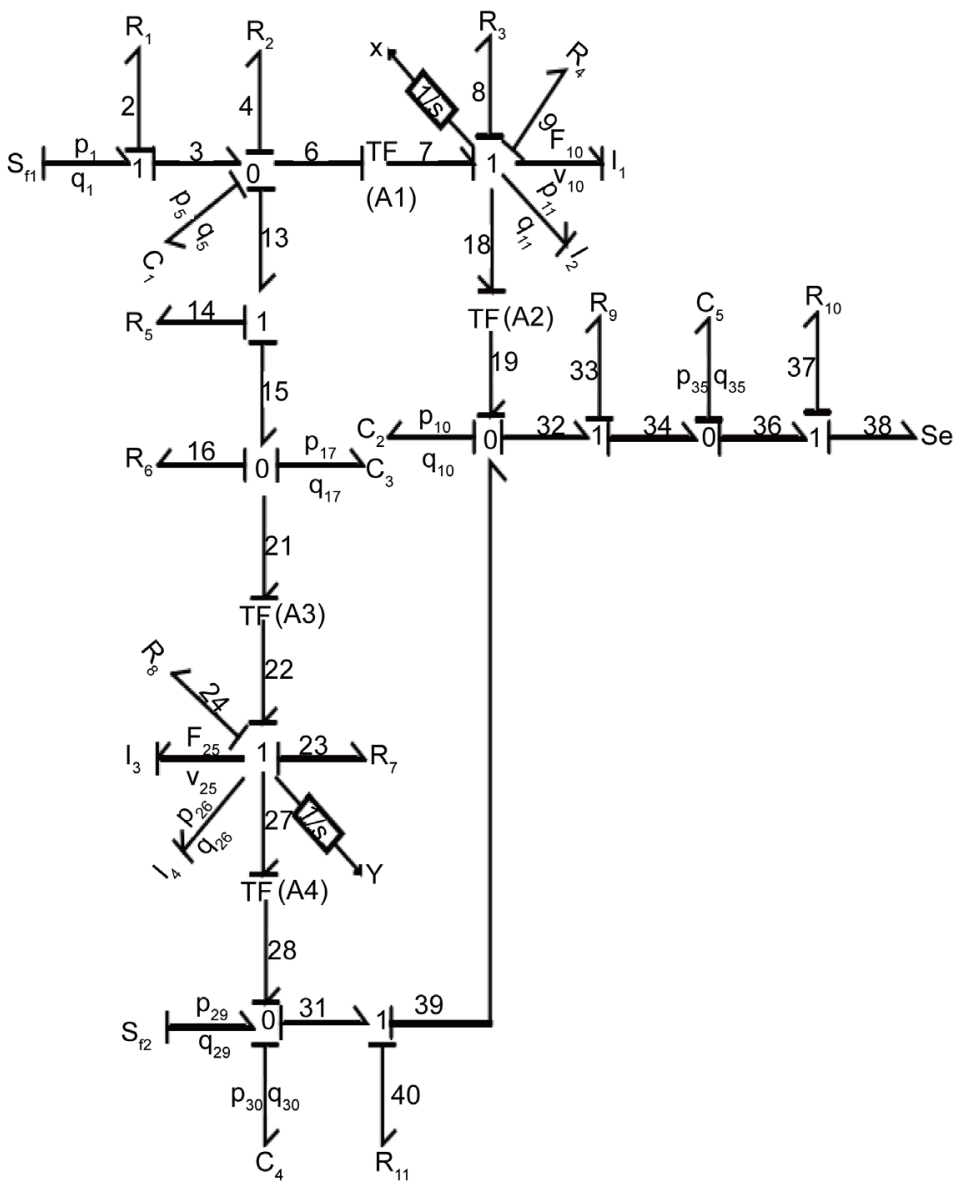

Figure 3. Power bond graph of hydraulic hammer for sleeve type. $\mathrm{Sf}_{1}$-The rated output of the hydraulic pump flow, (constant voltage source), $\mathrm{Sf}_{2}$-accumulator output flow, $\mathrm{Se}$ - The end of the return pipe pump pressure (a constant voltage source), $\mathrm{R}_{1}$-Liquid resistance along the way of inlet tube, $\mathrm{R}_{2}$-Leak fluid resistance at the piston, $\mathrm{R}_{3}$-Coulomb friction force piston suffered, $\mathrm{R}_{4}-\mathrm{Viscous}$ resistance of the piston in the process of moving, $\mathrm{R}_{5}$-The resistance along the way from the signal to the spool bore hole, $\mathrm{R}_{6}$-Leakage of liquid resistance in the sleeve valve spool chamber, $R_{7}$-Coulomb friction force that sleeve valve spool suffered, $R_{8}-V$ iscous resistance force sleeve valve suffered in the process of moving, $R_{9}$ - Leakage of liquid resistance between the drain chamber, $\mathrm{R}_{10}$ - Loss along the way of the return line, $\mathrm{R}_{11}$ - Leak fluid resistance within the sleeve valve spool, $\mathrm{C}_{1}$-Fluid capacity in front chamber of piston, $\mathrm{C}_{2}$-Fluid capacity in the right end of piston(fluid capacity in the outflow of sleeve valve, $\mathrm{C}_{3}$ - Liquid capacity in the inlet of sleeve valve, $\mathrm{C}_{4}$-Fluid capacity of accumulator, $\mathrm{C}_{5}$-Eqivalent liquid capacity in oil return line vessel(including hydraulic oil compression and pipeline deformation), $\mathrm{I}_{1}$ - The mass of the impact mechanism of piston, $\mathrm{I}_{2}$-Inertia of hydraulic oil in the chamber of piston, $\mathrm{I}_{3}$ - The mass of sleeve valve, $\mathrm{I}_{4}$ - The mass of the hydraulic oil in chamber of sleeve valve, $A_{1}$-Effective area of acting surface in the front of the piston, $A_{2}$-Effective area of acting surface in the back of the piston, $A_{3}$-Effective acting area of sleeve valve's inlet end, $A_{4}$-Effective acting area of sleeve valve in the left end.

\section{Determining the State Variables and Input Variables}

In deducing the mathematical model-state variables in the dynamic process, firstly the state variables should be confirmed. The state equation is first order differential equa- 
tions, among the variables are derivative relation. While in the power bond graph of system, only two variables of energy-storage element (capacitive element $C$ and inductive element $I$ ) can be considered as derivative or integral relation, so a pair of variables respectively from $C$ element and $I$ element must be chosen as state variables. Finally there are totally five independent variables, namely, $Q_{5}, Q_{10}, Q_{17}, Q_{30}, F_{10}, F_{25}$, five state variables are integration of independent variables.

$$
\int Q_{5} \mathrm{~d} t=V_{5}, \int Q_{10} \mathrm{~d} t=V_{10}, \int Q_{17} \mathrm{~d} t=V_{17}, \int Q_{30} \mathrm{~d} t=V_{30}, \int F_{10} \mathrm{~d} t=P_{10}, \int F_{25} \mathrm{~d} t=P_{25}
$$

Wherein, $V_{i}$ indicts the change of fluid volume caused by pressure change $(i=5,10$, 17, 30); $P_{10}$ indicts the piston mass, $P_{25}$ indict the mass of sleeve valve.

Taking fluid volume $V$, displacement $X$, solid or fluid momentum $I$ as state variables, and all these variables are first order derivative of original independent variables, then the relation of variables between $C$ element and $I$ element power bond can be transformed to algebraic relation between state variables and original independent variable., namely,

$$
p_{5}=\frac{V_{5}}{C_{1}}, p_{10}=\frac{V_{10}}{C_{2}}, p_{17}=\frac{V_{17}}{C_{3}}, p_{30}=\frac{V_{30}}{C_{4}}, v_{10}=\frac{P_{10}}{I_{1}}, v_{25}=\frac{P_{25}}{I_{3}}, p_{35}=\frac{V_{35}}{C_{5}}
$$

The first of state variables(equivalent to original independent variables can be deduced to algebraic function relation between dependent variable and input variable in the energy-storage element power bond. These relations of derivation are showed following formulas:

$$
\begin{aligned}
\dot{V}_{5} & =S_{f 1}-Q_{4}-Q_{13}-Q_{6} \\
& =S_{f 1}-\frac{p_{5}}{R_{2}}-\frac{p_{5}-p_{17}}{R_{5}}-A_{1} v_{10} \\
& =S_{f 1}-\left(\frac{1}{R_{2}}+\frac{1}{R_{5}}\right) p_{5}+\frac{p_{17}}{R_{5}}-A_{1} v_{10} \\
\dot{V}_{10} & =Q_{39}+Q_{19}-Q_{33} \\
& =Q_{40}+A_{2} v_{10}-\frac{p_{10}-p_{35}}{R_{9}} \\
& =\frac{p_{30}-p_{10}}{R_{11}}+A_{2} v_{10}-\frac{p_{10}-p_{35}}{R_{9}} \\
\dot{V}_{17} & =Q_{15}-Q_{16}-Q_{21} \\
& =Q_{13}-\frac{p_{17}}{R_{6}}-A_{3} v_{25} \\
& =\frac{p_{5}-p_{17}}{R_{5}}-\frac{p_{17}}{R_{6}}-A_{3} v_{25} \\
\dot{V}_{30} & =Q_{28}+S_{f 2}-Q_{31} \\
& =A_{4} v_{25}+S_{f 2}-Q_{40} \\
& =A_{4} v_{25}+S_{f 2}-\frac{p_{30}-p_{10}}{R_{11}}
\end{aligned}
$$




$$
\begin{aligned}
\dot{P}_{10} & =A_{1} P_{5}-F_{4}-F_{21}-A_{2} P_{10} \\
& =A_{1} \frac{V_{5}}{C_{5}}-R_{4} v_{10}-\frac{I_{2}}{I_{1}} P_{10}-A_{2} \frac{V_{10}}{C_{2}} \\
\dot{P}_{25} & =A_{3} P_{17}-F_{8}-F_{26}-A_{4} P_{30} \\
& =A_{3} \frac{V_{17}}{C_{3}}-R_{8} v_{25}-\frac{I_{26}}{I_{25}} P_{25}-A_{4} \frac{V_{30}}{C_{4}} \\
\dot{V}_{35} & =Q_{34}-Q_{36}=Q_{33}-\frac{s e}{R_{10}}=\frac{p_{10}-p_{35}}{R_{9}}-\frac{s e}{R_{10}} \\
\dot{X} & =v_{10}=\frac{P_{10}}{I_{1}} \\
\dot{Y} & =v_{25}=\frac{P_{25}}{I_{3}}
\end{aligned}
$$

Above equations are state variables of hydraulic breaker for sleeve valve type, which has nine independent variables. Actually, only seven equations are useful. Obviously, state equation showed in formulas (1)-(9) is a seven order mathematical model after simplifying the equations, which can calculate the state parameters of breaker for sleeve valve [4].

\section{Building Simulation Model Based on AMESim}

According to the working principle of hydraulic hammer for sleeve valve type, correspondent power bond graph can be built, the simulation model of hydraulic hammer for sleeve valve type can be built on the platform of AMESim, which take advantage of multidisciplinary intelligent modeling and simulation system can be showed in Figure 4 [5].

To simplify the simulation model, breaker should also be simplified during modeling as follow:

1) Suppose pump is a constant voltage source;

2) Ignore elastic deformation of the sleeve valve's cylinder;

3) Ignore the deformation resistance of accumulator diaphragm;

4) Ignore the oil quality of breaker inside the channel;

5) Ignore the mechanical friction of the piston and the valve body during moving;

6) Ignore the outside leakage of system.

Partial parameters are set as follow in the model: Pistonmass [6]: $4.3 \mathrm{~kg}$; mass of sleeve valve: $0.5 \mathrm{~kg}$; System pressure: $13 \mathrm{MPa}$;

The simulation result [7] is showed in Figures 5-9.

\section{Test Verification}

The simulation result is showed in above Figures 7-9 according to the above model, and the contrast between practical testing result and simulation result is showed in $\mathrm{Ta}$ ble 1. 


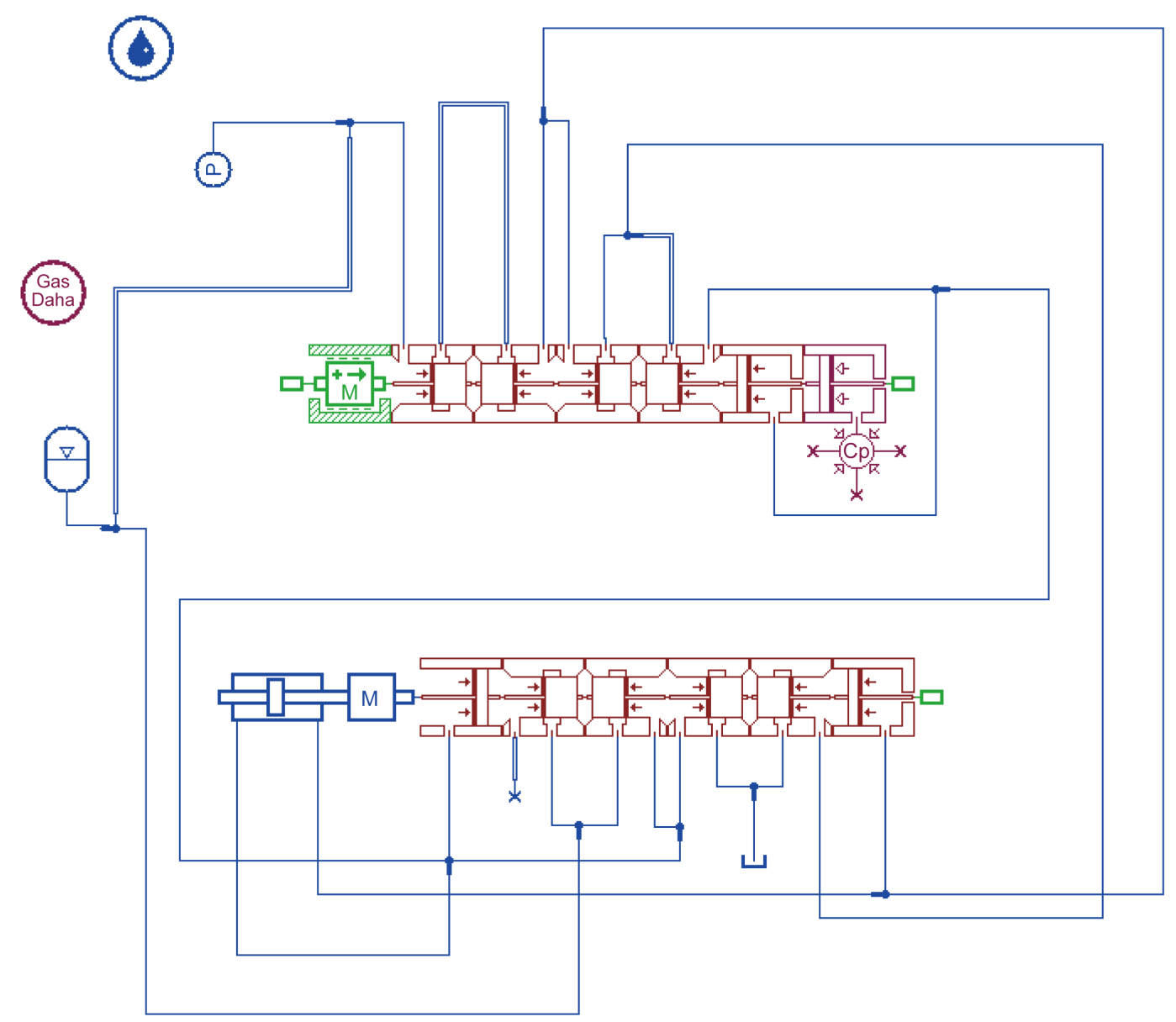

Figure 4. AMESim model of hydraulic hammer for sleeve type.

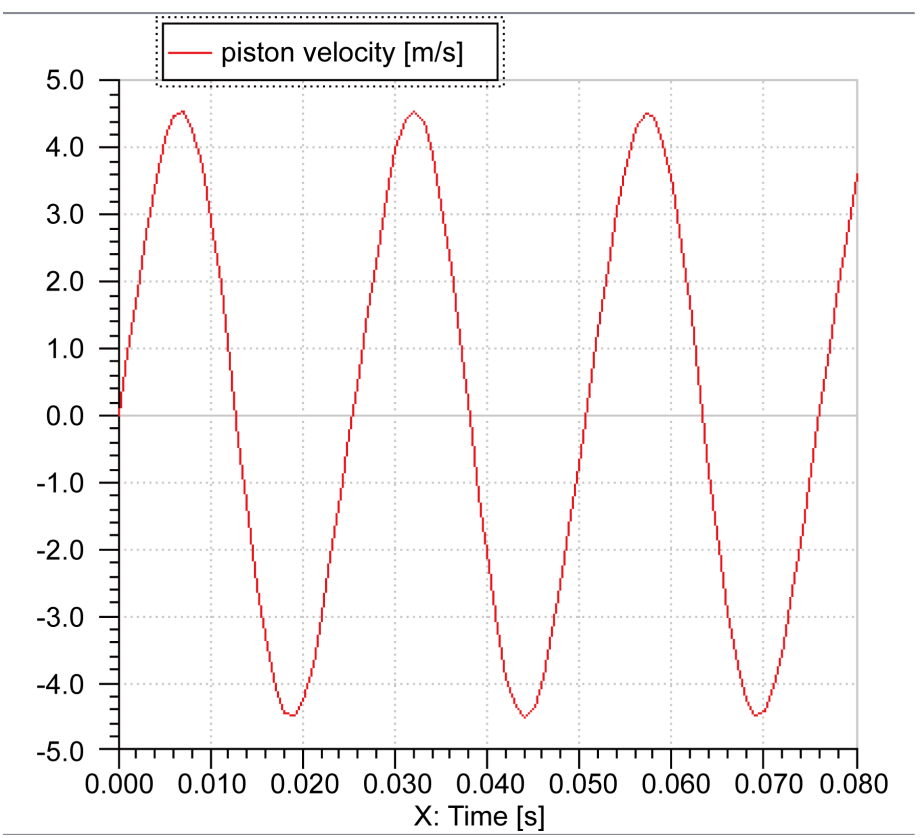

Figure 5. Curve of piston velocity. 


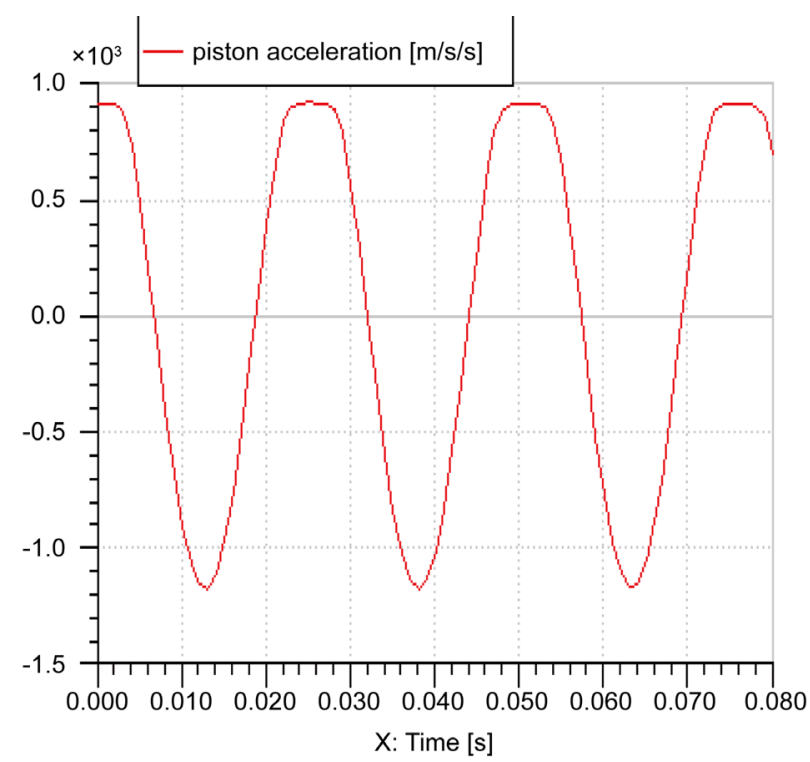

Figure 6. Curve of piston acceleration.

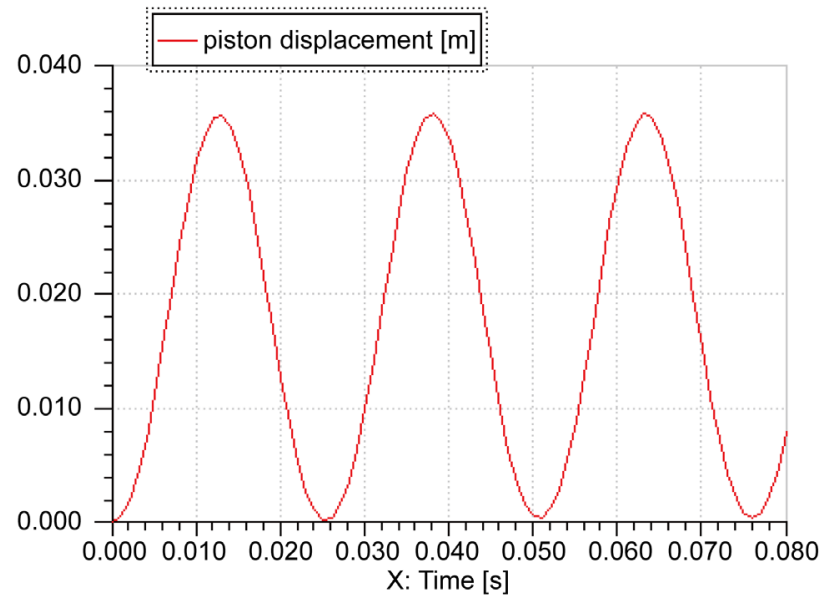

Figure 7. Curve of piston displacement.

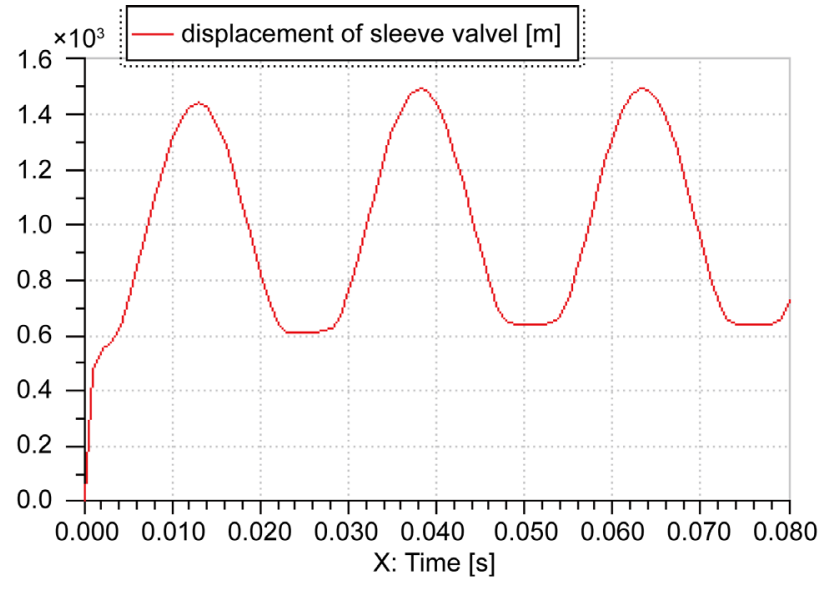

Figure 8. Curve of displacement for sleeve valve. 


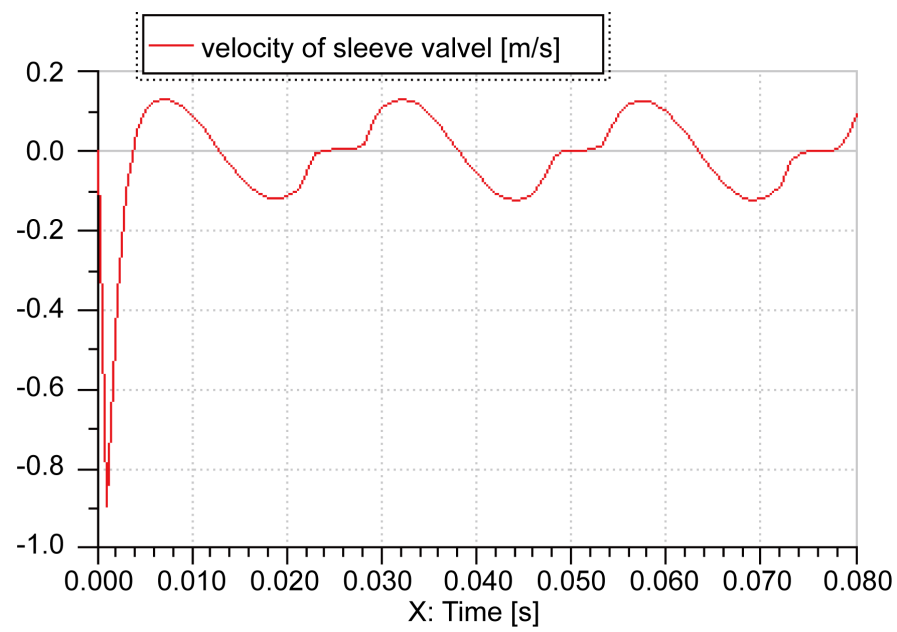

Figure 9. Curve of velocity for sleeve valve.

Table 1. Comparison between actual test and simulated result.

\begin{tabular}{ccccc}
\hline & Frequency & Impact velocity & Return velocity & Stroke \\
\hline Practical test & 50 & 4.9 & 4.5 & 35 \\
Simulation result & 52.63 & 4.62 & 4.52 & 35.67 \\
Deviation & $5.26 \%$ & $6.06 \%$ & $0.4 \%$ & $1.91 \%$ \\
\hline
\end{tabular}

Wherein, measurement of impact velocity can be through indirect pneumatic test [8], and its theory is that piston displacement can be worked out according to the pressure change of nitrogen chamber, and then piston velocity can also be worked out. Specifically, at the moment $t_{1}$, effective acting area of nitrogen chamber is $\mathrm{A}$, the position of piston is $X_{1}$, pressure and volume of nitrogen chamber is $P_{1}$ and $V_{1}$. But at the moment $t_{2}$, correspondent parameters are respectively $P_{2}, V_{2}$ when piston was in the position $X_{2}$. From the gas adiabatic equation, relation between above parameters can be showed below:

$$
P_{1} V_{1}^{K}=P_{2} V_{2}^{K}=P_{2}\left[V_{1}-\left(x_{2}-x_{1}\right) A\right]^{K}=P_{2}\left(V_{1}-\Delta x \cdot A\right)^{K}
$$

Piston displacement can be deduced as below:

$$
\Delta x=\frac{V_{1}}{A} \cdot\left[1-\sqrt[k]{\frac{P_{1}}{P_{2}}}\right]
$$

As the piston displacement is $\Delta x$, average velocity of piston from the position $x_{1}$ to $x_{2}$ can be calculated:

$$
\bar{v}=\frac{\Delta x}{\Delta t}=\frac{V_{1}}{A \cdot \Delta t} \cdot\left[1-\sqrt[k]{\frac{P_{1}}{P_{2}}}\right]
$$

$P_{1}, P_{2}$ can be obtained through the pressure sensor on the nitrogen indoor pressure timing sampling. When sampling time is small enough, the average velocity can be approximately equal to the velocity in the position $x_{2}$. So the maximum velocity must be 
gathered when the stroke finished, the maximum impact energy can be obtained as below

$$
E=\frac{1}{2} m \cdot v^{2}
$$

\section{Optimization of Related Parameters}

From the above Table 1, we can see that designed sizes and related parameters would cause deviation between practical result and testing result, so it is necessary to optimize the parameters [9].

To gain the maximum impact energy, structure parameters of the whole system must be optimized. While the end of piston impact velocity is the only parameters to determine the impact energy. Moreover, commonly, the end of piston impact velocity is no more than $12 \mathrm{~m} / \mathrm{s}$ with the material limitation.

Variables must be constrained according to character of breaker, nitrogen chamber model in the initial simulation model connects the velocity sensor model with the maximum piston velocity as the optimization target, which is showed as Figure 10 [10].

On the AMESim work environment, structure parameters of simulation model can be optimized with Design Exploration module. Finally, iteration process of optimization can be seen in Figure 11 and Figure 12. The optimization result can be showed in Table 2.

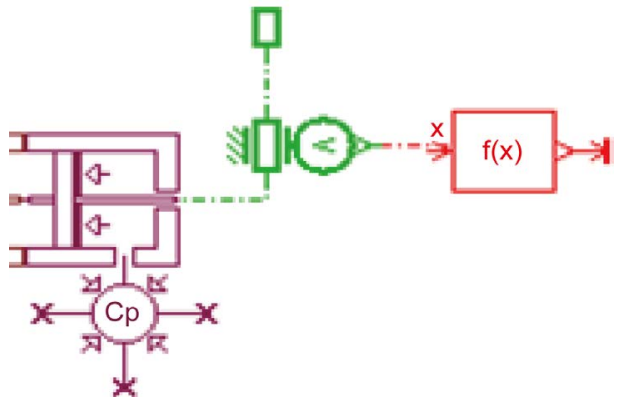

Figure 10. Measurement of piston velocity.

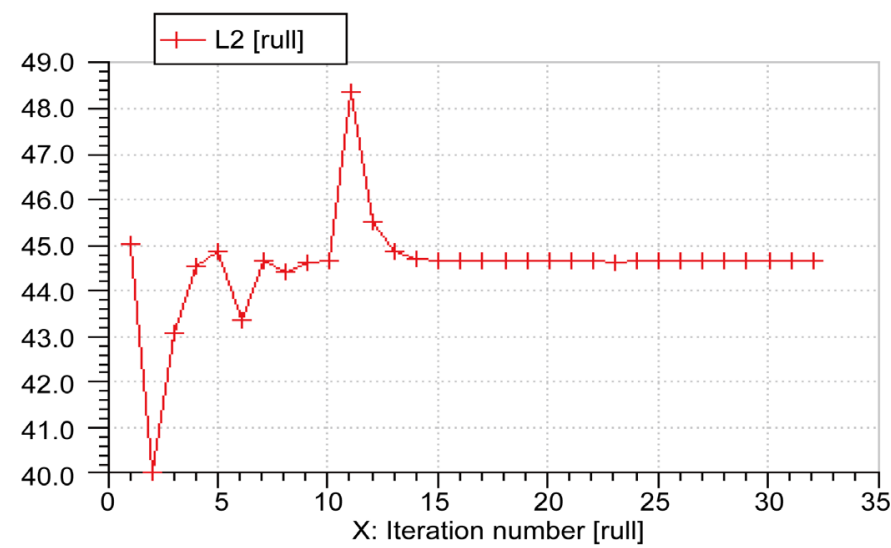

Figure 11. Back diameter of piston. 


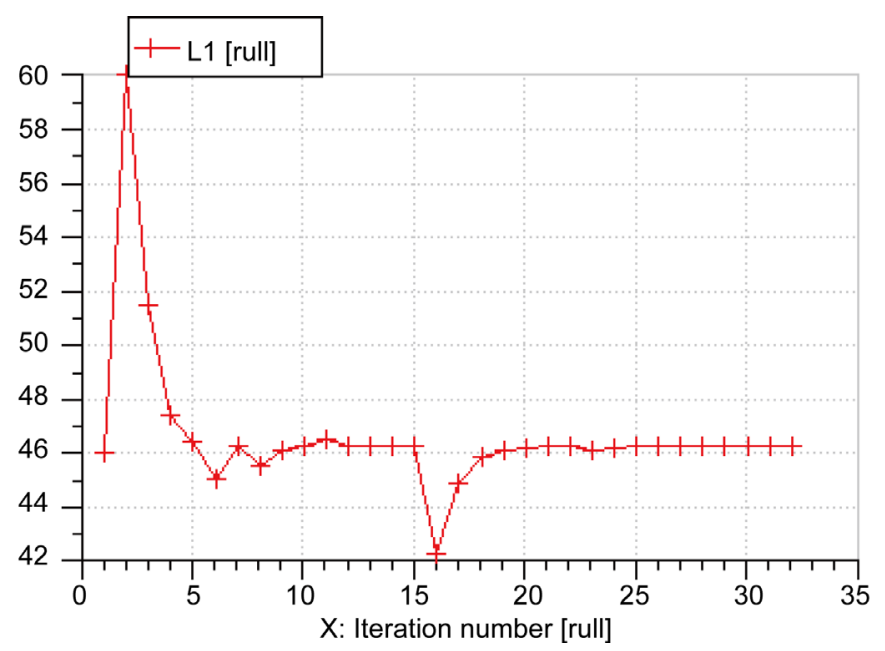

Figure 12. Front diameter of piston.

Table 2. Parameters of structures after optimizing.

\begin{tabular}{ccc}
\hline Structure parameters & Initial valve & Optimization valve \\
\hline Back diameter of piston $/ \mathrm{mm}$ & 45 & 44.7 \\
Front diameter of piston $/ \mathrm{mm}$ & 46 & 46.2 \\
\hline
\end{tabular}

\section{Conclusion}

In the paper, we analyze the working principle of hydraulic hammer for sleeve valve type and describe the law of motion of all working state. Models of key component describing the dynamic nonlinear mathematical model can be established with power bond graph. Under the AMESim circumstance, simulation model can be established and related parameters of component can be determined. Structure parameters of simulation model can be optimized with Design Exploration module. To make the design meet the practical working demands, we take piston velocity as the optimization target and choose the structure character of test machine as constraint variable, then gain the reasonable optimized structure parameters.

\section{References}

[1] Wang, X., Gong, J. and Zhou, X.F. (2006) The Development Situation of Hydraulic Impact Machine. Hydraulics and Pneumatics, No. 11, 49-52.

[2] He, Q.H. (2009) The Research and Design of Hydraulic Impact Mechanism. Central South University Press, Changsha.

[3] Yang, X.B. and Luo, M. (2012) Design Theory, Calculation Methods and Application of Hydraulic Hammer. Hefei Industrial University Press, Hefei.

[4] Luo, M. and Yang, X.B. (2005) The Structure Characteristics and Technical Progress of Hydraulic Hammer. Chinese Journal of Construction Machinery, No. 7, 43-46.

[5] Yang, G.P., Wang, R.L., Chen, B. and Gao, J.H. (2002) Modeling and Simulation of Hydraulic Hammer System. Chinese Journal of Highway, 15, 113-115.

[6] Fu, Y.L. (2005) Modeling and Simulation of AMESim System-Fromrentry to the Master. 
Beijing University of Aeronautics and Astronautics Press, Beijing.

[7] Liang, Q. and Su, Q.Y. (2014) AMESim Computer Simulation Guide of Hydraulic System. Machinery Industry Press, Beijing.

[8] Tian, S.J., Hu, Q.Y. and Zhang, H. (2012) Dynamic Character and Single Simulation of Hydraulic System. Dalian University of Technology Press, Dalian.

[9] Li, S.Q., Liu, H.P. and Zheng, Z.G. (2005) SQP and Virtual Prototyping Artillery Firing Stability Fusion Optimization. Weaponry Automation, 24, 1-2, 5.

[10] Ding, W.S. and Huang, X.D. (2010) Modeling and Simulation of Self-Assignment Hydraulic Breaker. Vibration and Shock, 29, 103-106.

Submit or recommend next manuscript to SCIRP and we will provide best service for you:

Accepting pre-submission inquiries through Email, Facebook, LinkedIn, Twitter, etc. A wide selection of journals (inclusive of 9 subjects, more than 200 journals)

Providing 24-hour high-quality service

User-friendly online submission system

Fair and swift peer-review system

Efficient typesetting and proofreading procedure

Display of the result of downloads and visits, as well as the number of cited articles

Maximum dissemination of your research work

Submit your manuscript at: http://papersubmission.scirp.org/

Or contact eng@scirp.org 